\title{
Enzyme Replacement Therapy from Birth in a Feline Model of Mucopolysaccharidosis Type VI
}

\author{
Allison C. Crawley, Krystyna H. Niedzielski, Elizabeth L. Isaac, Richard C.A. Davey, Sharon Byers, and John J. Hopwood \\ Lysosomal Diseases Research Unit, Department of Chemical Pathology, Women's and Children's Hospital, North Adelaide, South \\ Australia 5006, Australia
}

\begin{abstract}
We report evidence of a dose responsive effect of enzyme replacement therapy in mucopolysaccharidosis type VI cats from birth, at the clinical, biochemical, and histopathological level. Cats treated with weekly, intravenous recombinant human $\mathrm{N}$-acetylgalactosamine-4-sulfatase at $\mathbf{1}$ and $\mathbf{5}$ $\mathrm{mg} / \mathrm{kg}$, were heavier, more flexible, had greatly reduced or no spinal cord compression, and had almost normal urinary glycosaminoglycan levels. There was near normalization or complete reversal of lysosomal storage in heart valve, aorta, skin, dura, liver, and brain perivascular cells. No reduction in lysosomal vacuolation was observed in cartilage or cornea; however, articular cartilage was thinner and external ear pinnae were larger in some treated cats. Degenerative joint changes were not obviously delayed in treated cats. Skeletal pathology was reduced, with more normalized bone dimensions and with more uniform bone density and trabecular pattern clearly visible on radiographs by 5 to $6 \mathrm{mo}$; however, differences between 1 and $5 \mathrm{mg} / \mathrm{kg}$ dose rates were not clearly distinguishable. At a dose of $0.2 \mathrm{mg} / \mathrm{kg}$, disease was not significantly altered in the majority of parameters examined. Lysosomal storage was present in all tissues examined in the midterm mucopolysaccharidosis type VI fetus and increased rapidly in extent and severity from birth. (J. Clin. Invest. 1997. 99:651-662.) Key words: mucopolysaccharidosis VI - lysosomal storage diseases • genetics, medical $\bullet$ disease models, animal $\bullet$ dysostoses
\end{abstract}

\section{Introduction}

Lysosomal storage diseases result from a deficiency of one or more degradative enzymes necessary for normal cell metabolism. Mucopolysaccharidosis type VI (MPS VI; MaroteauxLamy syndrome $)^{1}$ is an inherited autosomal recessive lysoso-

Address correspondence to John J. Hopwood, Lysosomal Diseases Research Unit, Department of Chemical Pathology, Women's and Children's Hospital, 72 King William Rd., North Adelaide, South Australia, 5006, Australia. Phone: 6188204 7293; FAX: 6188204 7100; E-mail: jhopwood@medicine.adelaide.edu.au

Received for publication 16 September 1996 and accepted in revised form 2 December 1996.

1. Abbreviations used in this paper: $4 \mathrm{~S}, \mathrm{~N}$-acetylgalactosamine-4-sulfatase; BMT, bone marrow transplantation; CPC, cetylpyridinium chloride; ERT, enzyme replacement therapy; GAG, glycosaminoglycan; MPS VI, mucopolysaccharidosis type VI; rh4S, recombinant human 4 S.

J. Clin. Invest.

(C) The American Society for Clinical Investigation, Inc.

0021-9738/97/02/0651/12 \$2.00

Volume 99, Number 4, February 1997, 651-662 mal storage disease in which there is a deficiency of $N$-acetylgalactosamine-4-sulfatase (4S), leading to an accumulation of its substrate, dermatan sulfate in many tissues. Patients exhibit severe skeletal abnormalities including epiphyseal dysplasia, dwarfism, and facial dysmorphia, as well as widespread soft tissue pathology such as heart valve thickening, corneal clouding, joint stiffness, and carpal tunnel syndrome. Severely affected patients usually die in late childhood to early adulthood from cardiac or respiratory complications (1). MPS VI has also been described in cats $(2,3)$, rats $(4,5)$, and mice $(6)$, and pathology in these models closely parallels the disease found in humans. These animal models therefore provide valuable opportunities to develop and study potential new therapies for use in humans.

Bone marrow transplantation (BMT) is currently the only therapy in use for MPS patients. The limited efficacy of BMT on skeletal lesions in the MPS disorders $(7,8)$ may in part be due to initiating therapy after pathology is well established. BMT was lifesaving in the first MPS VI patient (9). Subsequent data has shown that this patient has maintained engraftment and continued freedom from life threatening problems (10), and is now gainfully employed 15 yr later (W. Krivit, personal communication). More MPS VI patients have been transplanted with similar results $(11,12)$. Although marrow donors are readily identified (National Marrow Donor Program, cord blood registry), and graft-vs.-host disease is diminished, there is still morbidity and mortality in a portion of patients. Despite BMT being considered a reasonable option in MPS VI patients, improved outcome by new therapies is needed.

The successful application of enzyme replacement therapy (ERT) in lysosomal storage disorders has been clearly demonstrated by Ceredase/Cerezyme ${ }^{\circledR}$ therapy in Gaucher patients (13-15), and ERT studies in several animal models of MPS disorders have shown promising results (16-20). Problems with tissue targeting of enzymes and large scale enzyme production have been largely overcome using enzyme produced by recombinant technology.

Our preliminary distribution studies in normal cats demonstrated widespread tissue uptake of a particular form of recombinant human $N$-acetylgalactosamine-4-sulfatase (rh4S) and a tissue half life of $\sim 2-4 \mathrm{~d}$. Although low dose ERT in MPS VI cats was unable to alter overall progression of clinical disease, results indicated a trend towards improved bone volume the earlier ERT was instituted (19). Short term studies (6 wk) at moderately high doses in the MPS VII mouse from birth demonstrated skeletal improvement and reduction in lysosomal storage in many soft tissues and in some areas of the central nervous system (17). In further experiments, mice studied for up to 12 mo after 6 wk ERT from birth showed increased life span and bodysize, and reduced skeletal deformities. This was despite return of lysosomal storage to levels seen in an untreated mouse to cells in bone by $29 \mathrm{~d}$ after last injection, and in the majority of remaining tissues by $85 \mathrm{~d}$ after last injection 
(20). This suggests that early institution of ERT during rapid bone growth is critical to improve overall skeletal development.

The purpose of this study was to evaluate the efficacy of weekly ERT with rh4S in MPS VI cats at three dose rates from birth for a duration of 5-11 mo. The development of clinical disease and resulting macroscopic and microscopic pathology with ERT was compared with disease progression in untreated MPS VI cats, including pathology found before birth. Parameters examined may have application in evaluating human patients undergoing ERT trials that are anticipated in the near future.

\section{Methods}

Enzyme production and purification. rh4S was produced in large amounts in Chinese hamster ovary cell culture, purified, and prepared for injection as described previously (19), except that the diluent used in the final assay for enzyme activity was changed to $0.05 \%$ Tween, which resulted in an increased specific activity; therefore, $55,000 \mathrm{nmol} / \mathrm{min}$ was used as the equivalent of $1 \mathrm{mg}$ of enzyme. A sample from each batch of purified rh4S was run on SDS-PAGE under reducing conditions. As previously reported, all batches contained a mixture of $\sim 70 \%$ precursor $(66 \mathrm{kD})$ and $30 \%$ mature $(57$, 43,7 , and $8 \mathrm{kD}$ ) polypeptides (19).

Experimental animals. All animals used in these studies were bred in an outdoor housed colony originally established from 'family 3 ' heterozygotes obtained from M. Haskins at the School of Veterinary Medicine, University of Pennsylvania (Philadelphia, PA) (21). Air dried blood films from newborn kittens were stained with MayGrunwald Giemsa and examined at $400 \times$ to detect characteristic changes in white cell morphology in MPS VI-affected animals. Diagnosis of MPS VI was subsequently confirmed by detection of increased urinary glycosaminoglycan (GAG) excretion using a modified alcian blue spectrophotometric method (22), and/or genotype analysis from blood spots (23). Normal control cats homozygous for the normal allele were selected by genotype analysis. Blood films of controls and cats undergoing ERT were taken at 1-2-mo intervals and stained and examined as above.

Enzyme administration and clinical evaluation in MPS VI cats. Nine MPS VI cats were injected weekly with intravenous rh4S starting at between 14 and $58 \mathrm{~h}$ after birth at variable dose rates for a duration of 5, 6 (175 $\pm 3 \mathrm{~d})$, and $11 \mathrm{mo}(323 \pm 13 \mathrm{~d}) .12 \mathrm{MPS}$ VI and 9 normal cats were included as untreated controls (Table I).

All cats undergoing ERT were given oral premedication from 6 wk of age with $1 \mathrm{mg}$ cyproheptadine (Periactin ${ }^{\circledR}$; Charles E. Frosst, Australia Pty. Ltd., Melbourne, Australia) and $1 \mathrm{mg}$ chlorpheniramine (Piriton ${ }^{\circledR}$, Glaxo, Australia Pty. Ltd.) orally at least 30 min before injection. Premedication dose was increased to $2 \mathrm{mg}$ of each, once body weight exceeded 2,000 g. Cats were weighed at the time of premedication, and enzyme dose was calculated accordingly. The enzyme was infused in volumes of up to $6 \mathrm{ml}$ into the cephalic vein for

Table I. Enzyme Replacement Therapy Dose Groups in MPS VI Cats, and Untreated Normal and MPS VI Controls: Dose Rates of Weekly rh $4 S$ and Duration of ERT

\begin{tabular}{lcc}
\hline \multicolumn{1}{c}{ Duration } & $6 \mathrm{mo}$ & $11 \mathrm{mo}$ \\
\hline MPS, no ERT & $5 \mathrm{~m}, 6 \mathrm{f}$ & $1 \mathrm{f}$ \\
MPS $0.2 \mathrm{mg} / \mathrm{kg}$ & $1 \mathrm{~m}$ & - \\
MPS $1 \mathrm{mg} / \mathrm{kg}$ & $2 \mathrm{~m}, 2 \mathrm{f}$ & $1 \mathrm{f}$ \\
MPS $5 \mathrm{mg} / \mathrm{kg}$ & $2 \mathrm{~m} *$ & $1 \mathrm{~m}$ \\
Normal, no ERT & $4 \mathrm{~m}, 3 \mathrm{f}$ & $1 \mathrm{~m}, 1 \mathrm{f}$ \\
\hline
\end{tabular}

*5 months duration; $\mathrm{m}$, male; $\mathrm{f}$, female. up to $20 \mathrm{~min}$. If signs suggestive of developing anaphylaxis occurred, enzyme infusion was stopped and reinstituted within $60 \mathrm{~min}$. Several enzyme preparations were tested negative for the presence of pyrogens using the Limulus lysate assay.

A clinical, neurological, and radiological examination was done at 3,5 , and 6 mo of age, and slit lamp examinations of the corneas were performed in conscious animals at 4.5 to 6 mo of age. In cats that were being observed for 11 mo duration, clinical, neurological, and radiological examinations were done at $3,5,7,9$, and $11 \mathrm{mo}$, and slit lamp examinations at 5 and 10 mo. Flexibility was subjectively measured by determining the ability to move the head laterally (maximum of $180^{\circ}$; i.e., nose touching flank) and to extend the coxofemoral joints (maximum of $\sim 180^{\circ}$ ).

Radiological examination under general anaesthesia was performed as described previously (19). Radiographs taken at 5-6 mo of age were evaluated "blind" for evidence of skeletal changes in response to therapy, compared with characteristic features of MPS VI in untreated controls as described previously (24).

Plasma samples collected from heparinized whole blood were tested for creatinine and urea using an autoanalyzer method (Sychron $\mathrm{CX}^{\circledR}$ Systems, Beckman Instruments, Inc., Fullerton, CA). Urine samples were collected by manual bladder expression under general anaesthesia while undergoing radiology procedures. Samples were stored without preservative at $-20^{\circ} \mathrm{C}$ until assayed. Urine creatinine was assayed using an autoanalyzer method (Sychron CX ${ }^{\circledR}$ Systems) and urine-specific gravity was measured using a digital refractometer (Atago UR-1 urine S.G. meter; Tokyo, Japan). Urinalysis reagent strips (Ames Neostix ${ }^{\circledR}$ N; Bayer Australia Ltd., Melbourne, Australia) were used to test for proteinuria.

Urinary GAG was purified by anion exchange chromatography, and then assayed for uronic content. Urine samples were diluted if necessary with deionized water to reduce specific gravity below 1.020 and mixed with column buffer and $\mathrm{pH}$ adjusted to achieve a final concentration of $0.1 \mathrm{M}$ Na-acetate, $\mathrm{pH} 5.0-5.5$. Aliquots of $0.375-2 \mathrm{ml}$ were applied to $1 \mathrm{ml}$ DEAE-Sephacel (Pharmacia LKB Biotechnology Inc., Uppsala, Sweden) equilibrated in $0.1 \mathrm{M} \mathrm{Na}$-acetate, $\mathrm{pH}$ 5, mixed continuously for at least $30 \mathrm{~min}$, and poured into a column. Sulfated GAG was eluted with $2 \mathrm{M} \mathrm{NaCl} / 0.1 \mathrm{M}$ Na-acetate, $\mathrm{pH} 5$. Fractions were assayed for uronic content using the hydroxydiphenyl method (25) and micrograms uronic per milligram creatinine calculated for each sample. To examine efficiency of binding, flow throughs from a selected number of samples were reapplied to fresh DEAE columns as outlined above. GAG from some samples was also purified using cetylpyridinium chloride (CPC) precipitation (26) and the yield of uronics (micrograms uronic per milligram creatinine) compared with the DEAE method.

Pathology. Cats undergoing ERT were killed at 5, 6, or 11 mo (see Table I), $4 \mathrm{~d}$ after the last enzyme injection, using an overdose of intravenous barbiturate. Postmortem included examination of shoulder, elbow, coxofemoral, and femorotibial joints, and removal of the dorsal vertebral arches from the fourth cervical to the fourth lumbar vertebrae to expose the spinal cord. Electron microscopy samples were fixed in $2 \%$ glutaraldehyde $/ 2 \%$ formalin in $0.1 \mathrm{M}$ sodium cacodylate buffer, $\mathrm{pH} 7.2$, overnight at $4^{\circ} \mathrm{C}$, and then postfixed in $1 \%$ osmium tetroxide before routine processing and embedding in Spurrs resin. $1-\mu \mathrm{m}$-thick survey sections stained with toluidine blue were evaluated at $100-400 \times$ to assess overall distribution of vacuolation due to lysosomal storage and subjectively graded $0-3+$ according to the degree of lysosomal vacuolation. These grades reflected: no (0), very mild $( \pm)$, mild $(1+)$, moderate $(2+)$, and severe $(3+)$ changes, and were relative to the variable severity of changes seen in different cell types in different tissues. Grading between untreated and treated MPS VI cats was also slightly different as changes in degree of vacuolation were not uniform in some tissues of treated cats. Selected samples were evaluated further under electron microscopy. Agematched normal and untreated MPS VI controls were used as controls for light and electron microscopy.

To evaluate development of pathology with age, tissues from an 
MPS VI fetus (confirmed by genotype analysis, reference 23) and a control littermate at $\sim 5.5 \mathrm{wk}$ gestation (age estimated from maternal abdominal palpation at $3 \mathrm{wk}$, and fetal size, reference 27) and MPS VI cats at $0,2,35,36$, and $53 \mathrm{~d}$ and 30 mo were collected for electron microscopy as above.

\section{Results}

Diagnosis at birth. In all blood films examined from 65 MPS VI cats bred within the colony, no normal eosinophils were observed at any age. Cells with numerous large clear vacuoles that filled the whole cytoplasm were observed instead, and these were assumed to be nonstaining eosinophils. These characteristic changes in eosinophils and in other white blood cell types were also seen in the midterm MPS VI fetus. Only the cats demonstrating nonstaining eosinophils were found to be homozygous for the MPS VI mutation by PCR-based genotype analysis of blood spots. Characteristic white cell morphology in untreated MPS VI cats (heavy neutrophil granulation, nonstaining eosinophils, and some vacuolated lymphocytes) was still present in MPS VI cats at all doses of ERT.

Enzyme administration. All cats exhibited mild reactions to injections on occasions throughout therapy as described previously (19), with onset from about 6-8 wk despite premedication. One cat $(5 \mathrm{mg} / \mathrm{kg})$ developed moderate anaphylactic reactions on repeated occasions after nearly 5 mo of therapy, including vomiting, trembling, increased respiratory rate, and pyrexia. Enzyme preparations used in this animal were negative for bacterial culture and were pyrogen free. One cat $(1 \mathrm{mg} / \mathrm{kg})$ on one occasion after 10 mo of therapy was given only one of the antihistamines and showed a moderate anaphylactic reaction that was not present on subsequent injections when given the full premedication.

Disease progression in MPS VI cats undergoing ERT: clinical examination. All MPS VI cats showed mild degrees of corneal clouding and cats undergoing ERT showed no changes in degree of clouding by slit lamp examination. Treated MPS VI cats were generally noticeably larger and heavier than untreated MPS VI controls, but weighed less than the normal controls (Table II). There was an apparent trend between increasing dose rate and increasing body weight for both males and females (Table II). They all retained features of MPS VI; however, there was variable resolution of facial dysmorphia

Table II. Body weight (Grams) of MPS VI Cats Undergoing ERT Compared With Untreated MPS VI and Normal Controls at 5 and $6 \mathrm{mo}$

\begin{tabular}{lcccc}
\hline & $n$ & $5 \mathrm{mo}$ & $n$ & $6 \mathrm{mo}$ \\
\hline Male & & & & \\
$\quad$ MPS, no ERT & 5 & $2053 \pm 321^{*}$ & 4 & $2211 \pm 349$ \\
MPS 0.2 mg/kg & 1 & 2391 & 1 & 2657 \\
MPS 1 mg/kg & 2 & 2658 & 2 & 2836 \\
MPS 5 mg/kg & 3 & $2744 \pm 341$ & 1 & 2740 \\
$\quad$ Normal, no ERT & 5 & $2976 \pm 201$ & 3 & $3279 \pm 204$ \\
Female & & & & \\
$\quad$ MPS, no ERT & 7 & $1856 \pm 355^{*}$ & 6 & $2066 \pm 280$ \\
$\quad$ MPS 1 mg/kg & 3 & $2241 \pm 244$ & 3 & $2302 \pm 183$ \\
Normal, no ERT & 4 & $2439 \pm 304$ & 3 & $2687 \pm 287$ \\
& & & &
\end{tabular}

$*$ Mean \pm 1 SD.
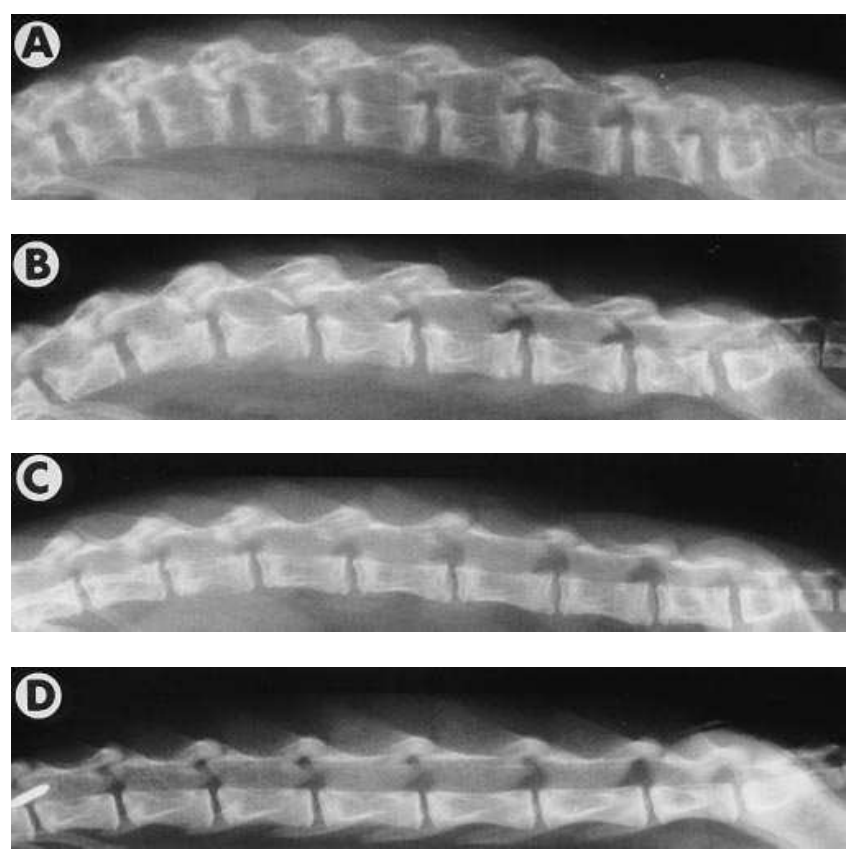

Figure 1. Radiographs of lateral view of the lumbar spine in $\sim 6$-mo-old cats, showing sclerotic, irregular epiphyses and radioopaque vertebral bodies in an untreated MPS VI cat $(A)$ compared with more uniform bone density between lumbar vertebral epiphyses and vertebral bodies, and longer narrower dimensions in an MPS VI cat at $1 \mathrm{mg} / \mathrm{kg}$ ERT (B), MPS VI cat at $5 \mathrm{mg} / \mathrm{kg}$ ERT $(C)$, and a normal control cat $(D)$. Milder degenerative changes in the vertebral articular facets were also seen in the MPS VI cats at 1 and 5 $\mathrm{mg} / \mathrm{kg}$ compared with the untreated MPS VI cat. The changes seen in the untreated MPS VI cat shown are representative of the majority of untreated MPS VI cats.

and thoracolumbar spinal kyphosis, near normalization of ear size, and increased body and neck length in individuals at 1 and $5 \mathrm{mg} / \mathrm{kg}$.

Untreated MPS VI cats showed moderate reduction in cervical spine flexibility, allowing only $90^{\circ}$ or less lateral movement by $5 \mathrm{mo}$ and $30^{\circ}$ by $11 \mathrm{mo}$, compared with the $5-\mathrm{mg} / \mathrm{kg}$ cats allowing $180^{\circ}$ at $5 \mathrm{mo}$ and $\sim 160^{\circ}$ at $11 \mathrm{mo}$ (normal is $\left.180^{\circ}\right)$. Cervical flexibility in the $1-\mathrm{mg} / \mathrm{kg}$ cats was slightly reduced at 5 and 6 mo $\left(130-160^{\circ}\right)$, but reduced to $90^{\circ}$ by $11 \mathrm{mo}$. The $0.2-\mathrm{mg} / \mathrm{kg}$ cat was no different from untreated MPS VI cats. Extension of the coxofemoral joint was very variable and unreliable for evaluating flexibility.

By 5 mo, 6/12 untreated MPS VI controls were showing evidence of mild to moderate neurological deficits in the hindlimbs, and 2/12 had hindlimb paralysis. By 6 mo, 7/12 (58\%) showed mild to moderate deficits and 4/12 (33\%) had full hindlimb paralysis, with only $1 / 12$ remaining neurologically normal. In contrast, all of the cats at $5 \mathrm{mg} / \mathrm{kg} \mathrm{(3/3)} \mathrm{showed} \mathrm{nor-}$ mal hindlimb neurology at $5 \mathrm{mo}$, and only $1 / 4$ of the cats at 1 $\mathrm{mg} / \mathrm{kg}$ showed very mild deficits at $6 \mathrm{mo}$. The two cats treated to $11 \mathrm{mo}$ at 1 and $5 \mathrm{mg} / \mathrm{kg}$ showed no hindlimb neurological deficits. The $0.2-\mathrm{mg} / \mathrm{kg}$ cat had mild neurological deficits by $6 \mathrm{mo}$.

Radiological examination. At 3 mo of age, the lumbar vertebrae of all the ERT MPS VI cats were overall more normal in shape than the untreated MPS VI controls. However, variability was already noticeable at this age in both groups, and 

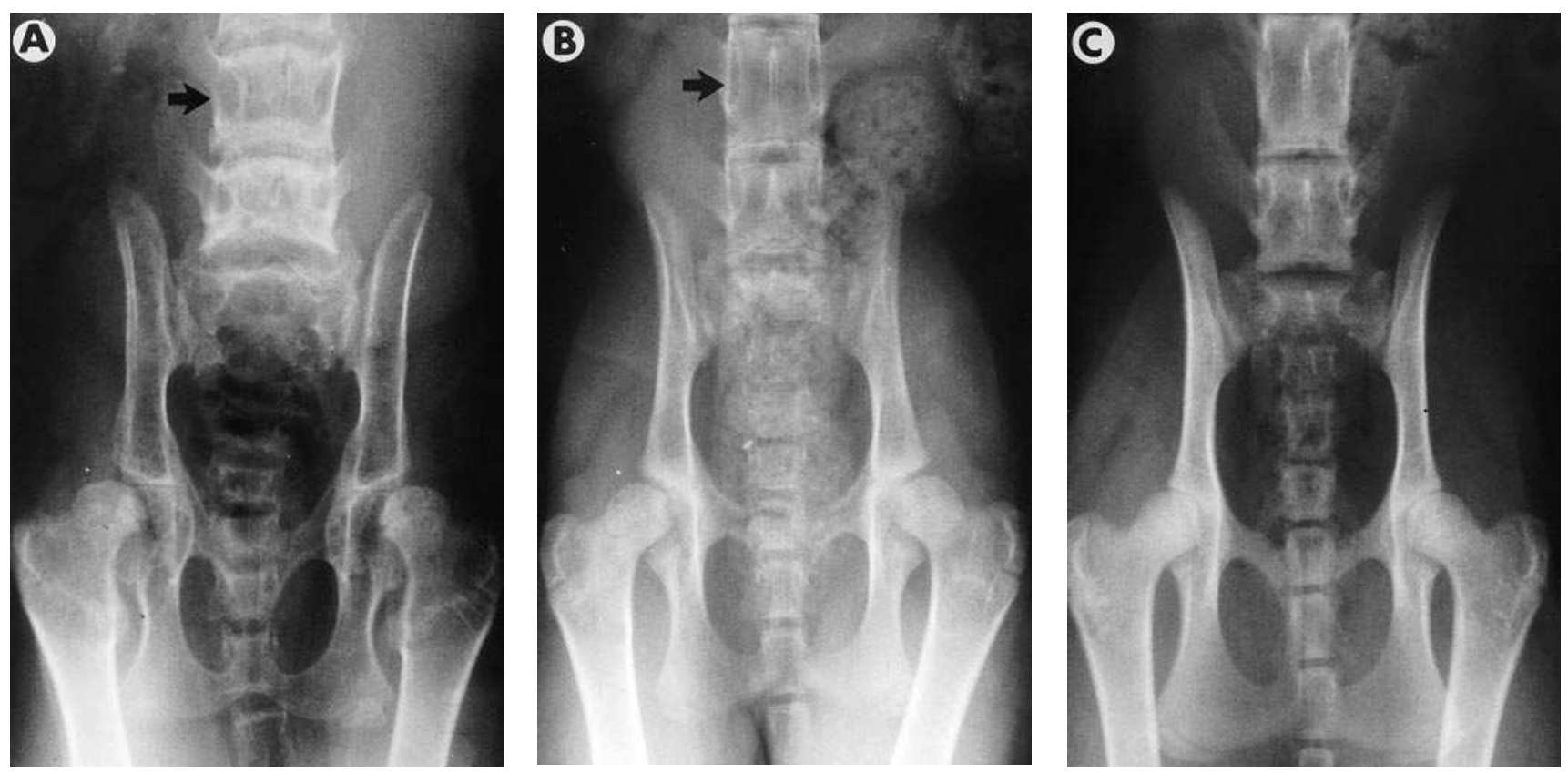

Figure 2. Radiographs of the ventrodorsal view of the pelvis and lumbar spine in $\sim 6$-mo-old cats. In addition to sclerotic lumbar vertebral endplates, the lumbar vertebrae and pedicles of the dorsal vertebral arches (arrow) were short and broad in untreated MPS VI cats $(A)$ ), compared with longer, narrower vertebrae and pedicles (arrow) in MPS VI cats at $5 \mathrm{mg} / \mathrm{kg}$ ERT $(B)$. A normal control is shown in $(C)$. The femoral head epiphyses were also a more normal shape in the treated MPS VI cats, although some degree of bilateral coxofemoral subluxation was still present.

compared with two untreated MPS VI controls with the mildest skeletal changes at this age, only $5 / 8$ of the cats at 1 and 5 $\mathrm{mg} / \mathrm{kg}$ had clearly longer and narrower lumbar vertebrae. The remaining 3/8 1- and $5-\mathrm{mg} / \mathrm{kg}$ cats and the $0.2-\mathrm{mg} / \mathrm{kg}$ cat were difficult to distinguish from the two mild untreated MPS VI controls. No obvious differences in cervical vertebral length and bone density/quality were observed between untreated and treated MPS VI cats at this age.

At 5-6 mo, it was possible to distinguish MPS VI cats undergoing ERT at 1 and $5 \mathrm{mg} / \mathrm{kg}$ from untreated MPS VI controls by looking at a combination of improved bone quality, density, and dimensions. These cats showed more uniform bone density between lumbar vertebral epiphyses and vertebral bodies, compared with sclerotic, irregular epiphyses and radioopaque (osteopenic) vertebral bodies seen in untreated MPS VI cats (Fig. $1, A-D$ ). In addition, the lumbar vertebrae and pedicles of the lumbar dorsal vertebral arches were longer and narrower compared with the short and broad vertebrae and pedicles in untreated cats, and there were milder degenerative changes seen in the lumbar vertebral articular facets (Figs. 1, $A-D$, and 2, $A-C$ ). Cervical vertebrae were also longer in these treated cats and cervical vertebral epiphyses were also larger and generally more regular, more so in the $5-\mathrm{mg} / \mathrm{kg}$ cats (Fig. 3, $A-C$ ). Trabecular pattern was distinctly more uniform in the distal femoral (Fig. 4, $A-D$ ) and generally in the proximal humeral epiphyses (Fig. 3, $A-C$ ) compared with a coarse trabecular pattern in untreated MPS VI cats. The subchondral bone surfaces in these epiphyses were also smoother, compared with untreated cats, which showed irregular bone surface contours. Overall, these epiphyses were larger in the cats at 1 and $5 \mathrm{mg} / \mathrm{kg}$; however, several individuals still had similar sized epiphyses to some of the untreated MPS
VI cats. This was also seen in the femoral head, and generally the head was rounder with less remodeling changes; however, all cats still showed some degree of bilateral hip subluxation (Fig. 2, $A-C$ ).

There was variability in the extent of changes for each of these features within the 1 and $5 \mathrm{mg} / \mathrm{kg}$ dose groups, and dose rate could not be accurately ascertained from these radiographic changes. Two of the untreated MPS VI cats had noticeably milder radiographic changes than the remaining untreated controls, and it was difficult to distinguish them from the $0.2 \mathrm{mg} / \mathrm{kg}$-treated cat, but they could still be distinguished from the 1 and $5 \mathrm{mg} / \mathrm{kg}$-treated MPS VI cats by lumbar vertebral bone density and cervical vertebral length.

By 11 mo of age, skeletal changes in response to ERT seen at 6 mo were still evident. In addition, bone density was more uniform in the patellae of both of the treated cats, and less remodeling was evident in the femoral heads.

Urinary GAG. All cats including MPS VI and normal controls showed a rapid reduction in the amount of total urine GAG with increasing age (Fig. 5, $A$ and $B$ ); however, levels in untreated MPS VI controls remained elevated above ERT MPS VI cats and normal controls at $\sim 10$ times normal. In all MPS VI cats undergoing ERT, there appeared to be a dose responsive reduction in the amount of urine GAG, with greatest reduction seen at $5 \mathrm{mg} / \mathrm{kg}$ to a level maintained at twice normal from 5 to $11 \mathrm{mo}$ of age. At $1 \mathrm{mg} / \mathrm{kg}$, this level was maintained at approximately three times normal. There also appeared to be a marginal reduction in the amount of urine GAG excreted in the $0.2-\mathrm{mg} / \mathrm{kg}$ cat compared with untreated MPS VI controls. An average of only 5\% (range 2-14\%) of DEAE-purified GAG rebound when flow throughs were reapplied to fresh columns. 

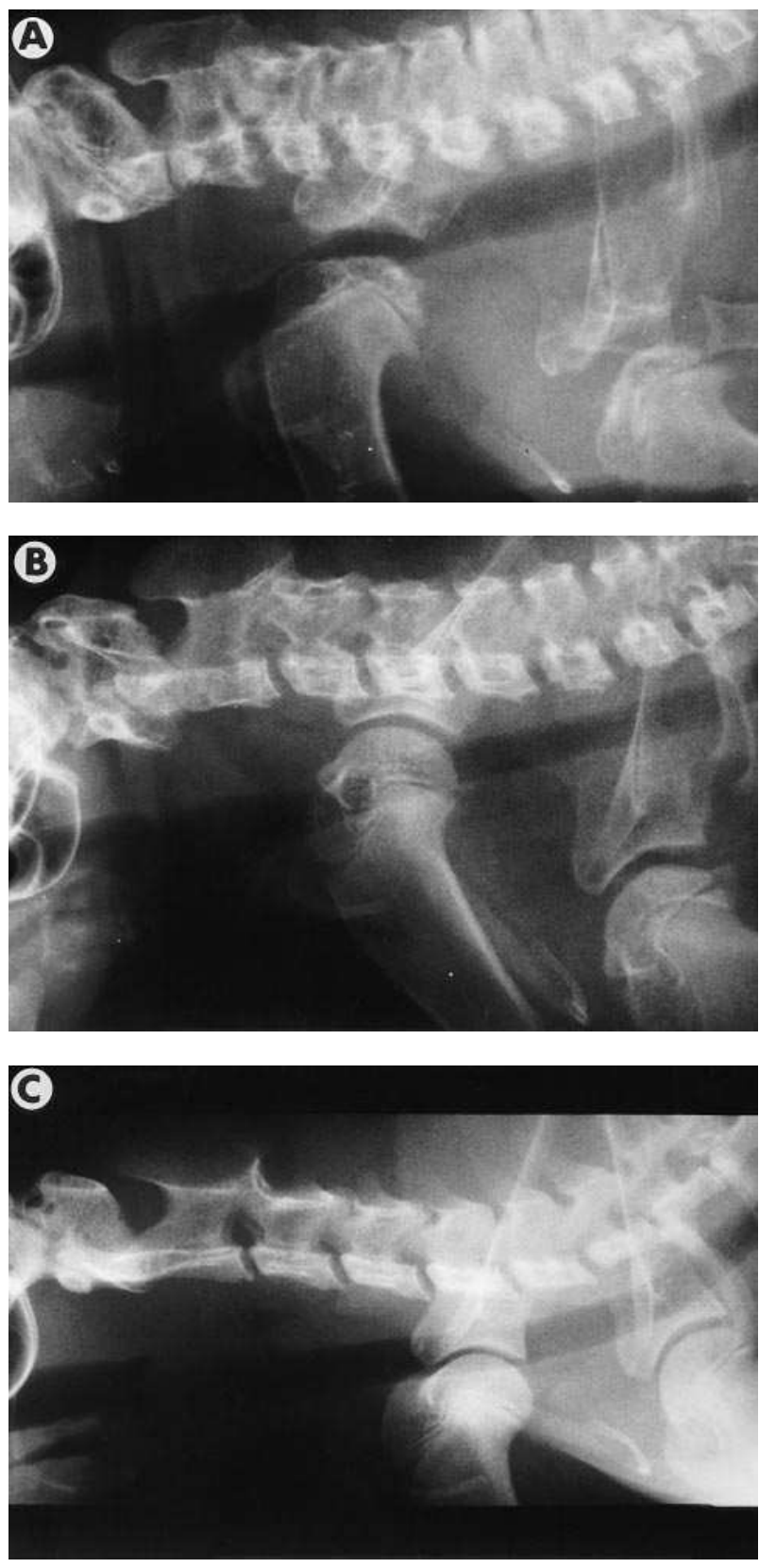

Figure 3. Lateral radiographs of the cervical spine and shoulder joints in $\sim 6$-mo-old cats: untreated MPS VI $(A)$, MPS VI at $5 \mathrm{mg} / \mathrm{kg}$ ERT $(B)$, and normal control $(C)$. Cervical vertebrae were longer and vertebral epiphyses were generally more regular in ERT MPS VI cats. Proximal humeral epiphyses generally had more uniform trabecular pattern, were larger, and in some ERT cats had smoother subchondral bone surfaces.

The yield of GAG precipitated by CPC compared with the yield from DEAE column purification was $30 \%$ in untreated MPS VI, $28 \%$ at $1 \mathrm{mg} / \mathrm{kg}$ ERT, $31 \%$ at $5 \mathrm{mg} / \mathrm{kg}$ ERT, and $48 \%$ in normal control cats. The percent precipitated by CPC was constant at all ages examined (3-11 mo).

Macroscopic pathology. At 6 mo of age, there was an overall impression of decreased articular cartilage thickness in most of the 1 and $5 \mathrm{mg} / \mathrm{kg}$-treated cats compared with the untreated MPS VI controls, seen best in the shoulder, hip, and knee joints. However, in some regions, such as over the ball of the proximal humerus and the ventral and caudal aspects of the distal femoral condyles, cartilage was still significantly thicker compared with normal controls. There was noticeable variation between individuals in both the untreated and treated MPS VI groups, with one $5-\mathrm{mg} / \mathrm{kg}$ cat appearing to have thickened cartilage in all joints to a similar degree to the untreated MPS VI cats. Improvements were seen in all the 1- and 5-mg/ $\mathrm{kg}$ cats in appearance and quality of subchondral bone, seen both from the cartilage surface and once articular cartilage was partially removed. There was great variability in treated and untreated MPS VI cats in the presence and severity of erosive lesions on the cranial aspect of the shoulder joint where the biceps tendon passes over the joint into the intertubercular groove. There was no correlation with presence or absence, or severity of these lesions in animals with normal mobility, or mild to moderate hindlimb neurological deficits, or complete hindlimb paralysis. However by $11 \mathrm{mo}$, the untreated and treated MPS VI cats at both doses all had erosive lesions in the shoulders, the most severe being found in the $5-\mathrm{mg} / \mathrm{kg}$ cat. This cat also had more severe fibrillation and cartilage flap formation in the elbows compared with the untreated 11-mo cat (the 1-mg/kg 11-mo cat was not examined). In the 30-mo untreated MPS VI cat, all the joints examined had severe erosion and/or fibrillation of cartilage, with loss of almost the entire articular cartilage on both joint surfaces in one shoulder and on both femoral heads.

The regions of spinal cord in untreated MPS VI cats most commonly affected by bony compression were T2-T9 and T13-L4, with the most severe lesions being found at T2-T5 and T13-L3 (Fig. $6 \mathrm{~A}$ ). Compression appeared to be due to bony constriction of the spinal canal in the intervertebral regions largely due to proliferation of bone in the dorsal articular facets and epiphyseal flaring of the vertebral bodies. In some cases, the cord was dorsolaterally compressed to almost a pear shape when viewed in cross section. At 6 mo, 9/11 (82\%) of the untreated MPS VI cats showed various degrees of cord compression, with only 2 cats showing no lesions. The $0.2 \mathrm{mg} / \mathrm{kg}$ treated cat had severe compression at L2-3 and mild upper thoracic lesions, and only $1 / 4$ of the $1-\mathrm{mg} / \mathrm{kg}$ cats had mild lesions at several cord levels. None of the $5-\mathrm{mg} / \mathrm{kg}$ cats had any evidence of spinal cord compression (Fig. $6 \mathrm{~B}$ ). Both of the 1and $5-\mathrm{mg} / \mathrm{kg}$ cats treated to $11 \mathrm{mo}$ had no cord compression compared with the one untreated MPS VI control, which had moderate to severe compression at 11 mo.

Light and electron microscopy. Dramatic reduction of storage to almost negligible levels was observed in the mitral heart valve and aorta at $5 \mathrm{mg} / \mathrm{kg}$ at 5 and $11 \mathrm{mo}$ (Fig. 7 and Table III). Similarly, at $1 \mathrm{mg} / \mathrm{kg}$ the degree of vacuolation due to storage was greatly reduced in these tissues; generally to a lesser degree, however, there was also negligible storage in the heart valve at $11 \mathrm{mo}$ in the $1-\mathrm{mg} / \mathrm{kg}$ cat. There appeared to be variability in the extent of reduction in storage in heart valve among the different animals in the $1 \mathrm{mg} / \mathrm{kg}$ dose group, and also between different blocks from the same sample in all the dose groups. Normalization of morphology in the aortic tunica media at $1 \mathrm{mg} / \mathrm{kg}$ was not uniform, and appeared to be corrected from the innermost layers, with a gradual increase in the degree of vacuolation of cells towards the tunica adventitia (Fig. 8). A thin band of vacuolated cells were present in the outer tunica media at $5 \mathrm{mg} / \mathrm{kg}$.

Storage vacuoles were also reduced in a dose responsive 

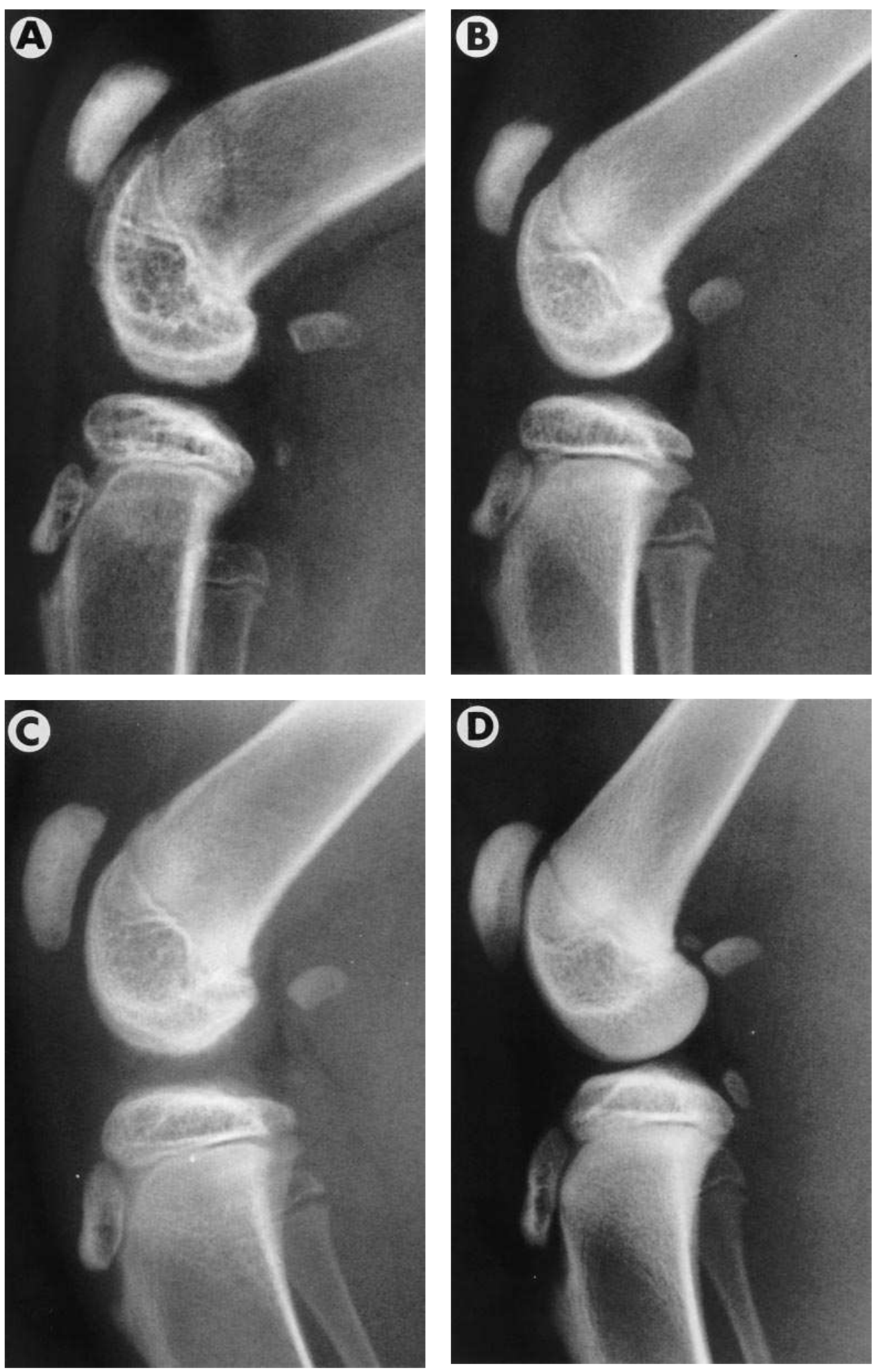

Figure 4. Lateral view of the right femorotibial joint in $\sim$ 6-mo-old cats: untreated MPS VI $(A)$, MPS VI at $1 \mathrm{mg} / \mathrm{kg}$ ERT $(B)$, MPS VI at $5 \mathrm{mg} / \mathrm{kg}$ ERT $(C)$, and normal control $(D)$. Trabecular pattern in the distal femur was more uniform and subchondral bone surfaces were smoother overall in MPS VI cats undergoing ERT at 1 and $5 \mathrm{mg} / \mathrm{kg}$.

manner in the 1- and $5-\mathrm{mg} / \mathrm{kg}$ cats in fibroblasts in most connective tissues including skin, dura (Table III), hip joint capsule, and kidney interstitium (data not shown), and also in perivascular cells in the cerebrum (Table III). There was no evidence of immune complex deposition in the renal glomerular basement membrane. In the $0.2-\mathrm{mg} / \mathrm{kg}$ cat, there was no change in the degree of storage in these tissues and in heart valve and aorta, compared with untreated controls, except for marginal reduction in the degree of storage in the perivascular cells in the central nervous system and in skin fibroblasts, and dura was not examined.

No change was seen in the degree of lysosomal vacuolation in corneal keratocytes and chondrocytes from articular cartilage and ear cartilage for all doses; however, storage was 
Table III. Lysosomal Storage in MPS VI Cats after 5-11 mo of ERT at Three Dose Rates

\begin{tabular}{|c|c|c|c|c|c|c|}
\hline Tissue/cell type & $\begin{array}{l}\text { MPS, no ERT } \\
\quad \geq 6 \mathrm{mo}\end{array}$ & $\begin{array}{c}\text { MPS } 0.2 \mathrm{mg} / \mathrm{kg} \\
6 \mathrm{mo} \\
(n=1)\end{array}$ & $\begin{array}{c}\text { MPS } 1 \mathrm{mg} / \mathrm{kg} \\
\quad 6 \mathrm{mo} \\
(n=4)\end{array}$ & $\begin{array}{c}\text { MPS } 1 \mathrm{mg} / \mathrm{kg} \\
11 \mathrm{mo} \\
(n=1)\end{array}$ & $\begin{array}{c}\text { MPS } 5 \mathrm{mg} / \mathrm{kg} \\
5 \mathrm{mo} \\
(n=2)\end{array}$ & $\begin{array}{c}\text { MPS } 5 \mathrm{mg} / \mathrm{kg} \\
\quad 11 \mathrm{mo} \\
(n=1)\end{array}$ \\
\hline Heart-valve fibroblasts & $3+$ & $3+$ & $1+-2+$ & 0 & $0- \pm$ & $\pm-1+$ \\
\hline Aorta-smooth muscle & $3+$ & $3+$ & $2+*$ & $1+-2+$ & $\pm-1+$ & $1+$ \\
\hline Skin-fibroblasts & $3+$ & $2+$ & $1+-2++$ & $2+$ & 0 & 0 \\
\hline Cornea-keratocytes & $3+$ & $3+$ & $3+$ & $3+$ & $3+$ & $3+$ \\
\hline Brain-perivascular cells & $3+$ & $2+$ & $0-1+$ & 0 & 0 & 0 \\
\hline Liver-Kupffer cells & $3+$ & 0 & 0 & 0 & 0 & 0 \\
\hline Cartilage-chondrocytes & $3+$ & $3+$ & $3+$ & $3+$ & $3+$ & $3+$ \\
\hline Dura mater (brain)-fibroblasts & $3+$ & NA & $\pm-2+*$ & NA & $0^{\S}$ & NA \\
\hline
\end{tabular}

$*_{n} n=2 ;{ }^{\ddagger} n=3 ;{ }^{\S} n=1$. NA, not available; 0 , no lysosomal vacuolation; \pm , very mild vacuolation; $1+$, mild; $2+$, moderate; $3+$, severe lysosomal vacuolation.
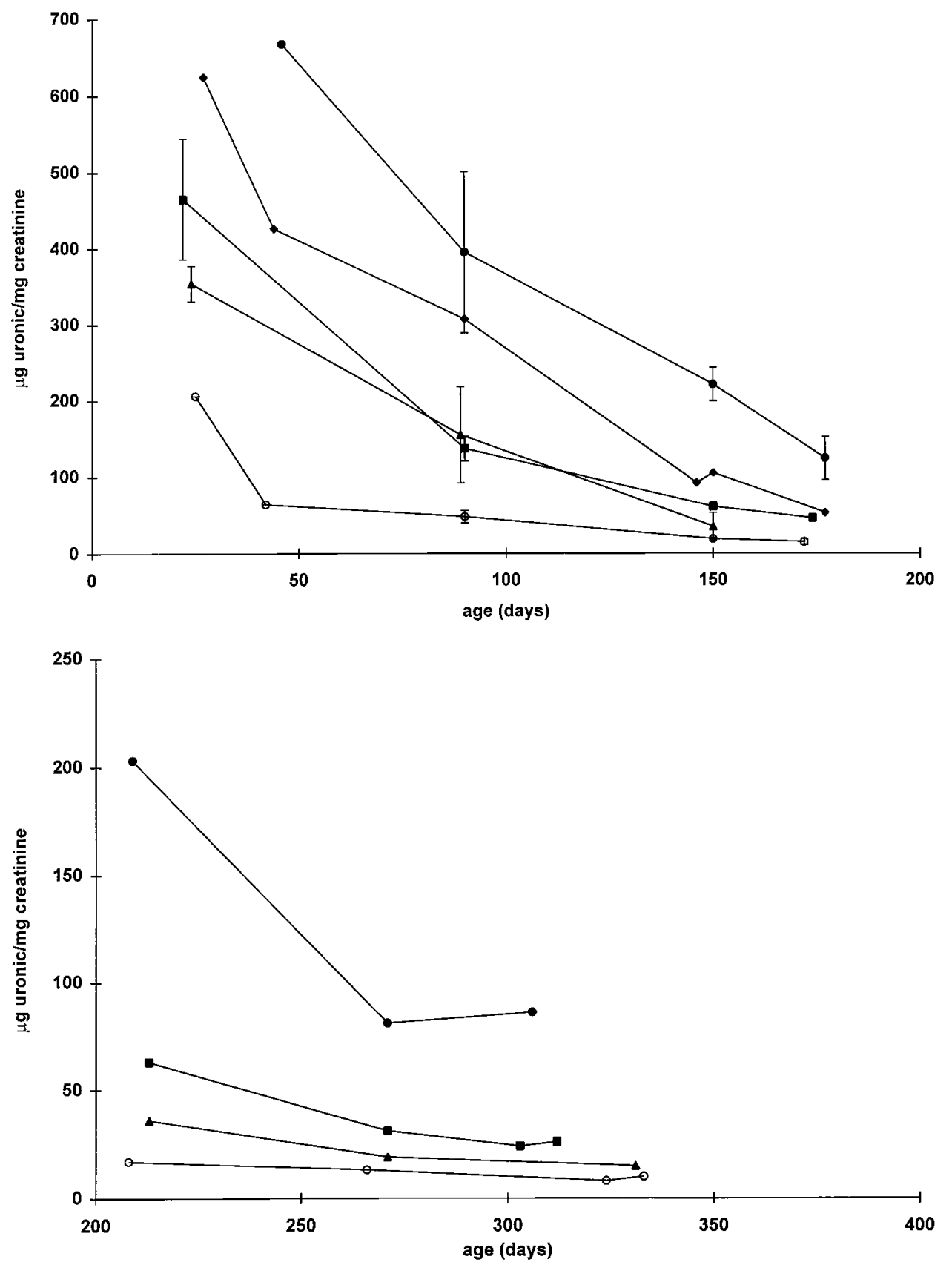

Figure 5. (Top) Urinary excretion of glycosaminoglycans in MPS VI untreated $(\mathbf{\bullet} ; n=3)$, MPS $0.2 \mathrm{mg} / \mathrm{kg}$ $(\diamond ; n=1)$, MPS $1 \mathrm{mg} / \mathrm{kg}(\mathbf{\square} ; n=3)$, MPS $5 \mathrm{mg} / \mathrm{kg}(\mathbf{\Lambda} ; n=3)$, and normal $(\bigcirc ; n=3$ to 4$)$ cats, from birth to 6 mo. Error bars $=1$ SD. Points with no error bars indicate $n<3$. (Bottom) Urinary excretion of glycosaminoglycans in MPS VI untreated (๑), MPS $1 \mathrm{mg} / \mathrm{kg}(\boldsymbol{\square})$, MPS $5 \mathrm{mg} / \mathrm{kg}(\boldsymbol{\Lambda})$, and normal $(\bigcirc)$ cats, from 7 to 11 mo $(n=1$ for all points). 

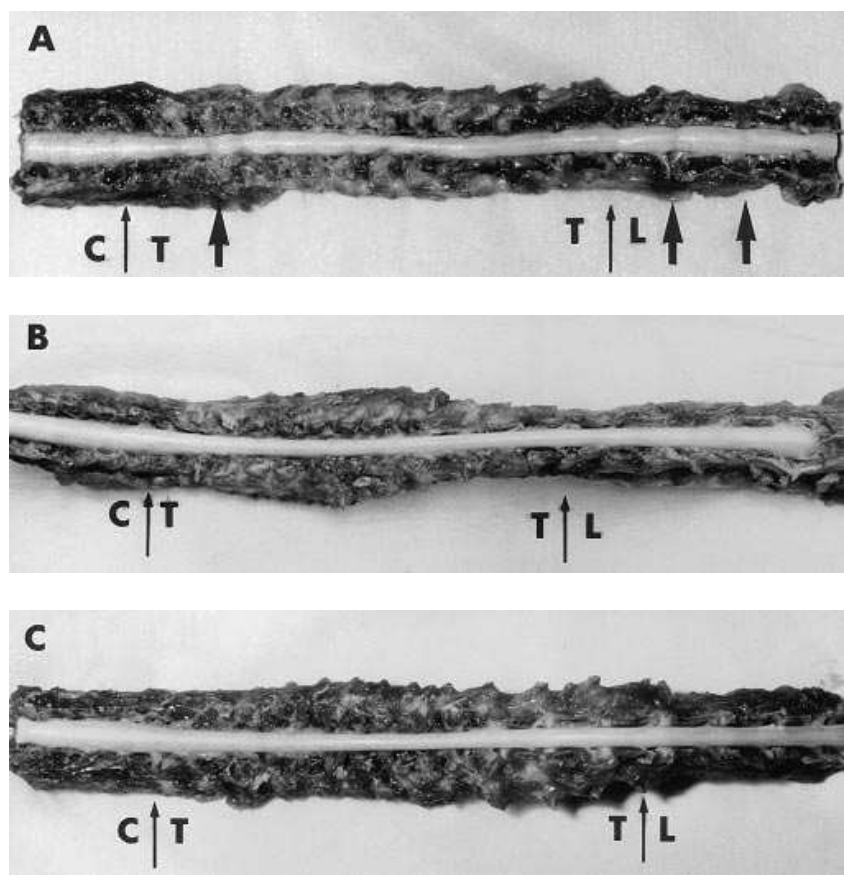

Figure 6. Spinal cord in situ after dorsal vertebral arches were removed from the fourth cervical to the fourth lumbar vertebrae: $(A)$ untreated MPS VI cat showing severe cord compression at multiple levels in the upper thoracic and thoracolumbar regions; $(B)$ MPS VI at $5 \mathrm{mg} / \mathrm{kg}$ ERT with no cord compression; and $(C)$ normal control cat. Photographs not standardized for magnification. Thin arrows indicate junctions of cervical $(C)$ and thoracic $(T)$, and thoracic $(T)$ and lumbar $(L)$ levels, and bold arrows indicate regions of severe cord compression.

cleared from Kupffer cells in the liver at all dose rates, including $0.2 \mathrm{mg} / \mathrm{kg}$ (Table III).

Lysosomal storage was evident in all MPS VI fetal tissues examined; however, it was to a lesser degree than that found in newborn and older kittens. Maximal storage in the majority of tissues was seen by $35 \mathrm{~d}$ of age (Table IV).

\section{Discussion}

The aim of this study was to evaluate the efficacy of intravenous ERT from birth in MPS VI cats with rh4S at three dose rates, namely $0.2,1$, and $5 \mathrm{mg} / \mathrm{kg}$, administered weekly. The

Table IV. Age-related Lysosomal Storage in Untreated MPS VI Cats

\begin{tabular}{lccccc}
\hline \multicolumn{1}{c}{$\begin{array}{c}\text { Tissue/cell type } \\
\text { MPS no ERT }\end{array}$} & $\begin{array}{c}\text { Fetal } \\
(n=1)\end{array}$ & $\begin{array}{c}\text { Newborn } \\
(n=2)\end{array}$ & $\begin{array}{c}35 \mathrm{~d} \\
(n=2)\end{array}$ & $\begin{array}{c}53 \mathrm{~d} \\
(n=1)\end{array}$ & $\begin{array}{c}\geq 175 \mathrm{~d} \\
(n \geq 3)\end{array}$ \\
\hline Heart-valve fibroblasts & $1+$ & $\pm-2+$ & $3+$ & $\mathrm{NA}$ & $3+$ \\
Aorta-smooth muscle & $\pm-1+$ & $1+-2+$ & $3+$ & $3+$ & $3+$ \\
Skin-fibroblasts & $1+$ & $1+-2+$ & $3+$ & $3+$ & $3+$ \\
Cornea-keratocytes & \pm & $1+*$ & $3+*$ & $3+$ & $3+$ \\
Brain-perivascular cells & $\mathrm{NA}$ & $\pm-1+$ & $2+$ & $2+$ & $3+$ \\
Liver-Kupffer cells & $1+$ & $2+-3+$ & $3+^{*}$ & $3+$ & $3+$ \\
Cartilage-chondrocytes & $1+$ & $2+-3+$ & $3+^{*}$ & $\mathrm{NA}$ & $3+$ \\
& & & & &
\end{tabular}

$* n=1$. NA, not available; 0 , no lysosomal vacuolation; \pm , very mild vacuolation; $1+$, mild; $2+$, moderate; $3+$, severe lysosomal vacuolation.
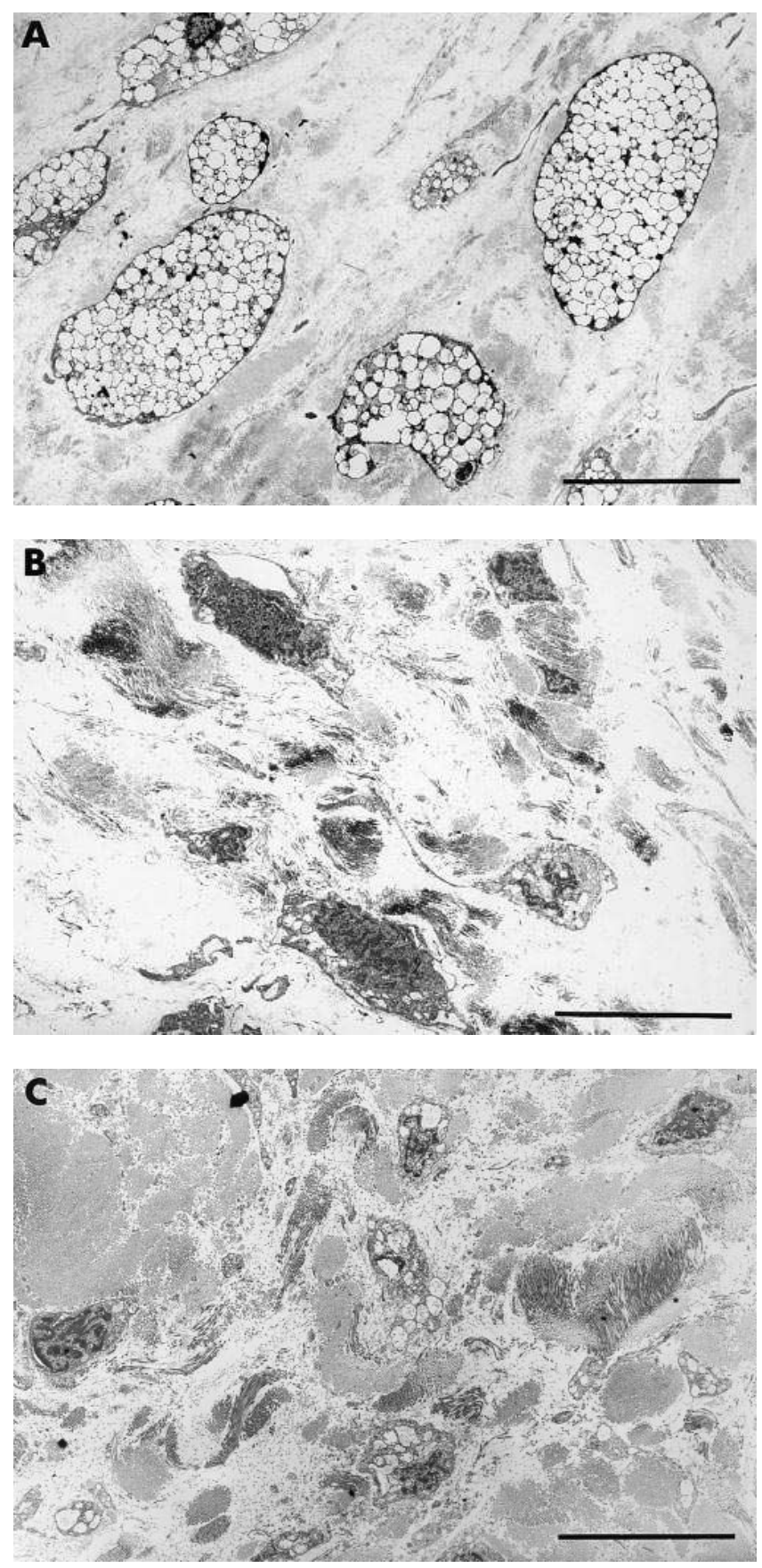

Figure 7. Connective tissue cells in mitral valve: $(A)$ in an untreated MPS VI cat, cells are enlarged and distended with storage vacuoles, $(B)$ no storage vacuoles are observed in an MPS VI cat at $5 \mathrm{mg} / \mathrm{kg}$ ERT, $(C)$ normal control cat. Bar $=10 \mu \mathrm{m}$.

development of MPS VI pathology from fetus to adult was also evaluated.

Results presented demonstrate a dose responsive effect of ERT, with clear improvement at $1 \mathrm{mg} / \mathrm{kg}$ and greatest effect at $5 \mathrm{mg} / \mathrm{kg}$. ERT was effective in reducing development of soft tissue and skeletal pathology, correlating well with improvements observed clinically and with reductions of urinary GAG. The $0.2-\mathrm{mg} / \mathrm{kg}$ dose appeared insufficient to significantly alter progression of soft tissue and skeletal disease in the MPS VI cat. 

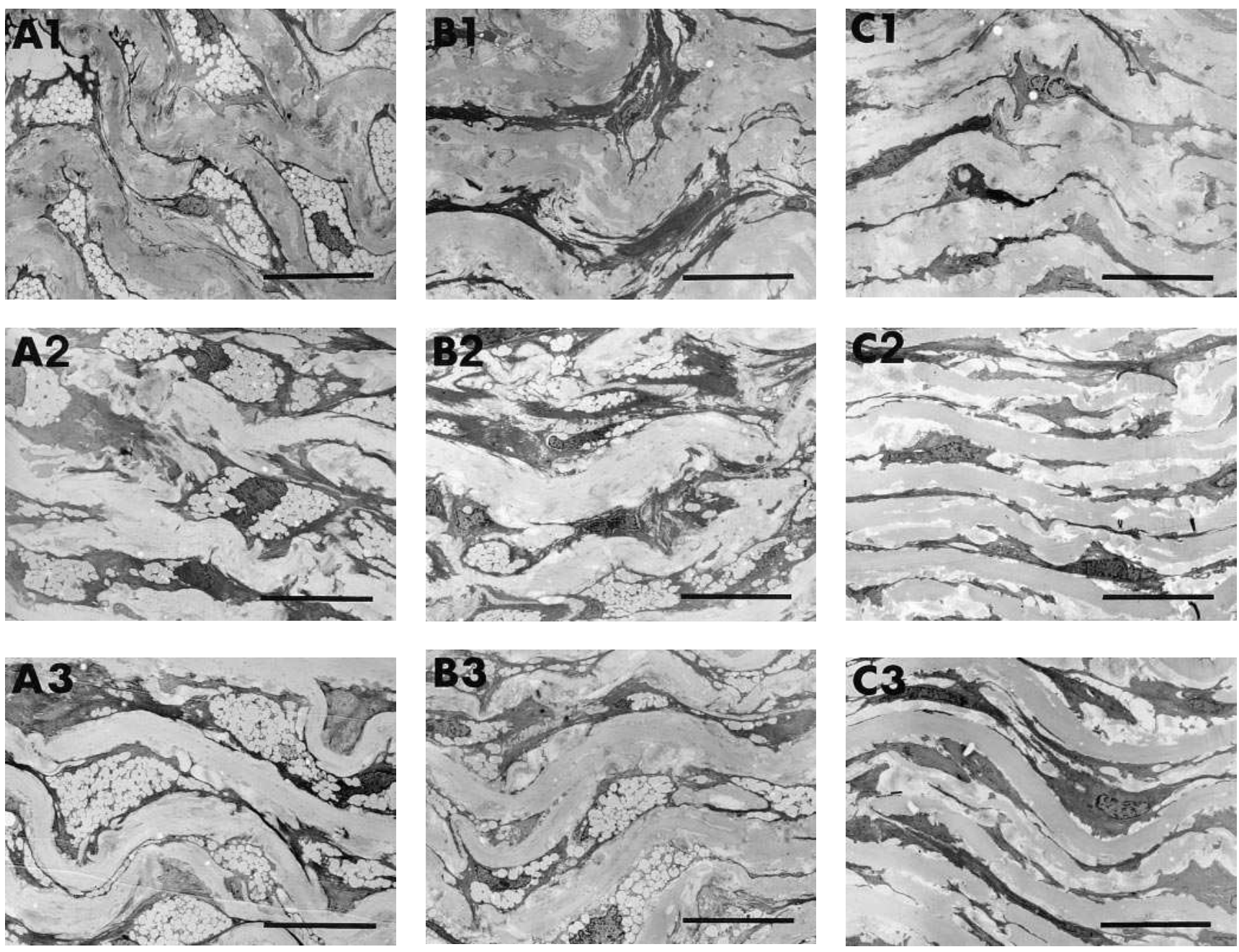

Figure 8. Transverse section of aorta, with photographs from inner lumenal (1), middle (2), and outer (3) regions of the Tunica media, in: (A1$A 3)$ an untreated MPS VI cat, (B1-B3) an MPS VI 1-mg/kg ERT cat showing absence of storage in inner third (B1), mild storage in majority of cells extending slightly more into the central third (B2), and almost maximal storage of cells in outermost quarter (B3), and (C1-C3) a normal control cat. Bar $=12.5 \mu \mathrm{m}$.

Prevention or reduction of development of lysosomal storage in the majority of tissues examined at 1 and $5 \mathrm{mg} / \mathrm{kg} \mathrm{sug}$ gests that ERT is likely to lead to significant improvements in quality of life in human patients. Respiratory difficulty and cardiac valve insufficiency due to soft tissue thickening leads to death in many human MPS patients, and restriction of joint movement also causes major incapacitation (1). Therefore improvements seen in mitral heart valve and the hip joint capsule provide great impetus to progress to therapy trials in human MPS VI patients. It is also interesting that decreases in lysosomal storage were not uniform in some tissues, seen clearly from the gradual increase in degree of lysosomal vacuolation towards the outer layers of the aortic tunica media (Fig. 8), with greatest improvement seen at $5 \mathrm{mg} / \mathrm{kg}$. This suggests a dose-related gradient of diffusion of rh $4 \mathrm{~S}$ in dense connective tissues.

Comparison of efficacy in these studies with our preliminary ERT studies in older cats at variable doses (19) indicates that reduction in skeletal pathology is dependent on both dose and timing of onset of therapy. The radiographic improvements seen in the 1 - and 5-mg/kg ERT cats could not be clearly separated according to dose rate. However, using bone histomorphometric analysis, a more sensitive method of evaluating skeletal response to therapy, a definitive dose responsive effect of ERT on skeletal development was demonstrated (S. Byers, J.D. Nuttall, A.C. Crawley, J.J. Hopwood, K. Smith, and N.L. Fazzalari, manuscript submitted for publication). Morphometric analysis in our previous study suggested a trend towards improved bone volume with onset of ERT at 2 and 7 mo of age compared with 12 mo (19). From these and other studies (20), it is evident that early institution of therapy is critical to alter overall skeletal disease progression. The presence of fetal storage in MPS VI kittens and the rapid development of severe and widespread soft tissue pathology by $35 \mathrm{~d}$ of age also emphasizes the importance of early initiation of therapy. Methods to screen human neonates for lysosomal storage diseases, particularly the MPS, have been developed (P. Meikle, personal communication). This should allow the detection of MPS patients well before clinical signs are obvious, and therefore enable therapies to begin at a time that would maximize their benefits.

Directly comparable results of responses to BMT and ERT in the MPS VI cat are currently not available. BMT studies in 
the MPS VI cat have shown some subjective clinical improvement in mobility and general appearance, together with reduction in urine GAG excretion (28), but no histological changes have been published. Radiographic changes after BMT have not been described, although slight changes in skeletal disease were seen $(28,29)$, and bone morphometric analysis in BMT cats has shown some increases in trabecular bone volume (BV/ TV\%) (30, 31).

Therapy at all doses of ERT was unable to alter the degree of lysosomal vacuolation in corneal keratocytes, correlating with persistence of corneal clouding by slit lamp examination. This concurs with our previous study with lower dose ERT for a long duration (19), and also with ERT studies performed in the MPS VII mouse (17) and MPS I dog (18). Reciprocal corneal graft experiments in MPS VI and normal cats suggest that pathology in the cornea is not reversible (32), probably due to its avascular nature; however, reversal of corneal pathology demonstrated in BMT MPS VII mice (33) but not seen in ERT MPS VII mice is interesting (17).

Lysosomal storage in chondrocytes appears refractory to BMT and ERT in MPS animal models $(17-19,33)$ except for slight changes seen in BMT MPS I dogs (34). A maintained dose of $5 \mathrm{mg} / \mathrm{kg}$ rh $4 \mathrm{~S}$ for up to $11 \mathrm{mo}$ is the highest dose used in ERT studies in MPS animal models to date. Despite this, ERT was unable to reduce the degree of lysosomal distension in articular cartilage chondrocytes, and also to prevent development of degenerative joint changes. Degenerative joint disease is probably due to a combination of reduced cartilage integrity and the ability of the subchondral bone to support the articular cartilage, as erosive lesions first appear in high load bearing regions such as the shoulder. However, the subjective reduction in articular cartilage thickness and overall increased size in epiphyses indicate that improved transformation of cartilage into bone has occurred with therapy. Increased ear size, although not objectively measured, also indicates that chondrocytes can function to some degree despite the presence of severe lysosomal distension that seems to obscure the nucleus and all other cytoplasmic organelles.

Patient welfare due to immune-mediated complications with the use of therapeutic proteins is an important issue, as well as the effects on efficacy of the administered protein. The presence of antibodies in Gaucher patients undergoing ERT with Ceredase ${ }^{\circledR}$ does not appear to alter efficacy of therapy, although a relatively small number of patients experienced various symptoms suggestive of immediate hypersensitivity reactions (35). Kittens undergoing ERT exhibited signs of reactions to enzyme infusions from an early age. This was partially controlled by antihistamine premedication; however, in one $5-\mathrm{mg} / \mathrm{kg}$ cat, moderate anaphylactic type reactions became resistant to premedication. The clinical reactions in ERT cats may have resulted from complement activation by immune complexes as seen in Gaucher patients undergoing ERT (35), or from direct binding of immunoglobulins (typically $\mathrm{IgE}$ ) to mast cells, although detection of IgE antibody class is currently unavailable in cats. Titers against rh4S in these ERT cats treated from birth by intravenous infusion were not significantly different from untreated MPS VI and normal controls (D. Brooks, B.M. King, A.C. Crawley, S. Byers, and J.J. Hopwood, manuscript submitted for publication). In contrast, MPS I dogs with a null mutation (36) undergoing ERT and myoblast-mediated gene therapy produced $\mathrm{IgG}$ antibodies against human and canine $\alpha$-L-iduronidase, respectively (18,
37). MPS VI cats produce a small amount of $4 \mathrm{~S}$ protein that appears to be inactive toward a 4-sulfated trisaccharide substrate (23). The presence of some protein may modify the immune response by reducing the likelihoood of the production of high titer reactive antibodies. There was no evidence of renal glomerular immune complex deposition or impaired renal function (data not shown) in the ERT cats compared with the controls for the duration of therapy studied. Including additional ERT studies from birth currently in progress, a total of 23 cats have undergone ERT. One kitten died at $5 \mathrm{wk}$ due to congenital cardiac abnormalities, and three died at 12-13 wk from severe feline parvoviral enteritis, confirmed histologically. No other mortalities have occurred.

In our preliminary studies, a high titre against rh4S was observed in one cat in which therapy was started at 7 mo. The circulating titer in this cat was reduced after enzyme infusion, and a dose-related inactivation of rh4S was observed in vitro with addition of the high titer plasma to rh4S (19). This indicates that it is possible that in the presence of high antibody titers, enzyme inactivation could occur in cats undergoing ERT. In high titer immunized rats, altered intracellular routing and more rapid turnover of rh4S was observed (D. Brooks, B.M. King, A.C. Crawley, S. Byers, and J.J. Hopwood, manuscript submitted for publication). In several ERT cats with similar titers to cats in this study, intracellular routing of rh4S was normal (D. Brooks, unpublished observation). Tissue enzyme distribution in two treated cats from this study was no different from that observed in untreated controls (S. Byers, unpublished observations). We therefore conclude that the efficacy of therapy in cats undergoing ERT in this study has not been significantly compromised by production of antibodies against rh4S.

An improved method for quantitating urine GAG was developed based on a previous method (38) to overcome problems experienced when analyzing highly concentrated urines using an alcian blue dye binding assay (22). The anion exchange column binds all sulfated GAG, and allows almost complete separation from urine pigments and proteins that interfere with uronic quantitation. Some uronic content not quantifiable due to pigment was evident in the flow through, and probably contains nonsulfated chondroitin (39). Compared with CPC precipitation, which fails to precipitate GAG below 3,000 D (26), the DEAE method, although more labor intensive, allows greater sensitivity in detecting changes in GAG excretion associated with therapies.

MPS VI cats can be reliably and rapidly distinguished at birth by looking for the presence of nonstaining eosinophils on blood films, as all cats were later confirmed MPS VI by genotype analysis. No discrepancies have occurred in a total of 65 MPS VI cats evaluated using both methods. Eosinophils stained normally in three human MPS VI patient blood films stained under the same conditions (A. Crawley, unpublished observation). Alroy et al. (40) examined MPS VI cat blood films stained with Wright-Giemsa, and they described cells with both eosinophilic and dark purple to black granules that were interpreted to be eosinophils. These differences in eosinophil staining are not easily explained. It is also unknown why many normal/heterozygote cats within our colony, confirmed by genotype analysis, show heavy cytoplasmic granulation in neutrophils, which has only been previously described in MPS VI cats (A. Crawley, unpublished observation). Therefore, the presence of neutrophil granulation was unreliable for detec- 
tion of MPS VI at birth. Our observations of no reduction in granulation of neutrophils at all doses of ERT must be interpreted cautiously, as there may be other causes of neutrophil granulation present within our colony.

Clinical heterogeneity seen in both untreated and treated MPS VI cats, including between siblings, making analysis of results more difficult, was also observed by other researchers $(41,24)$. This suggests that greater difficulties in evaluation of efficacy will be met in human MPS VI patients undergoing ERT, because of the many different genotypes expected in human patients. Results of this study must also be interpreted in the light of sample size, which was limited due to the enormity of the task of enzyme production and purification.

In conclusion, ERT from birth at 1 and $5 \mathrm{mg} / \mathrm{kg} \mathrm{rh} 4 \mathrm{~S}$ was shown to be very effective at reducing development of pathology in all tissues examined except cartilage and cornea, with the greatest effect seen at $5 \mathrm{mg} / \mathrm{kg}$. There was also radiographic evidence of improved bone trabecular pattern, bone density and dimensions, and a dramatic reduction of urinary GAG excretion. Clinically treated cats were more flexible, larger, and the majority had normal hindlimb neurology and no spinal cord compression at postmortem. Storage pathology was present in all fetal tissues examined, and rapidly increased after birth. MPS VI morphology in cartilage chondrocytes and corneal keratocytes was unchanged at high doses of ERT; however, there was a suggestion of improved transformation of cartilage into bone in higher dose cats. The majority of cats experienced mild clinical reactions to enzyme infusions and there was no suggestion of immune-mediated reduction in enzyme efficacy or impairment of renal function, or development of titres against rh4S compared with controls. Further studies are in progress to evaluate enzyme modifications to improve cartilage penetration, and to look at increased dose frequency. A detailed evaluation of the response to ERT started after birth, but still before skeletal maturity, using more effective doses than in our previous studies, would also yield important information on the response to therapy once skeletal pathology is established.

\section{Acknowledgments}

The authors gratefully acknowledge Lesley Powell, Christine Stanford, Vanessa Hobbs, Karen McDougall, Christine Merrett, and other animal care staff at the Institute of Medical and Veterinary Science for the daily care of the cat colony. We also thank Dr. Michael Hammerton for slit lamp examinations of the cats, Dr. John Finnie for specialized veterinary pathology, Dr. Denise Noonan for additional veterinary support, Mrs. Barbara King for assistance with weekly injections, and Dr. Lakshmi Kumaratilake for Limulus lysate assay. Helpful discussions with Dr. Doug Brooks regarding immunological apsects, Dr. Bruce Foster and Dr. Nick Fazzalari for their expertise involving the skeletal system, Dr. Tony Bourne regarding histology, and Dr. Bill Vernau and Mr. Brian Matthews regarding hematology were also greatly appreciated. Support by Viv Muller and Peter Clements involving aspects of enzyme production is also gratefully acknowledged. Technical assistance from the WCH Radiology Department, sample processing by the WCH Electron Microscopy Unit, and preparation of photography by Foundation Studios was also appreciated. We would also like to thank CSL Limited for the provision of media containing rh4S.

This work was supported by the WCH Foundation, Channel 7 Children's Research Foundation, CSL Limited, and the National Health and Medical Research Council of Australia. The original cats heterozygous for MPS VI (National Institutes of Health DK-25759) given by Prof. Mark Haskins from the University of Pennsylvania is gratefully acknowledged.

\section{References}

1. Neufeld, E.F., and J. Muenzer. 1995. The mucopolysaccharidoses. In The Metabolic and Molecular Basis of Inherited Disease. 7th ed. C.R. Scriver, A.L. Beaudet, W.S. Sly, and D. Valle, editors. McGraw-Hill Inc., New York. 24652494.

2. Jezyk, P.F., M.E. Haskins, D.F. Patterson, W.J. Mellman, and M. Greenstein. 1977. Mucopolysaccharidosis in a cat with arylsulfatase B deficiency: a model of Maroteaux-Lamy syndrome. Science (Wash. DC). 198:834-836.

3. Haskins, M.E., G.D. Aguirre, P.F. Jezyk, and D.F. Patterson. 1980. The pathology of the feline model of mucopolysaccharidosis VI. Am. J. Pathol. 101: 657-674.

4. Yoshida, M., H. Ikadai, A. Maekawa, M. Takahashi, and S. Nagase. 1993. Pathological characteristics of mucopolysaccharidosis VI in the rat. J. Comp. Pathol. 109:141-153.

5. Yoshida, M., J. Noguchi, H. Ikadai, M. Takahashi, and S. Nagase. 1993 Arylsulfatase B deficient mucopolysaccharidosis in rats. J. Clin. Invest. 91:10991104.

6. Evers, M., P. Saftig, P. Schmidt, A. Hafner, D.B. McLoghlin, W Schmahl, B. Hess, K. von Figura, and C. Peters. 1996. Targeted disruption of the arylsulfatase B gene results in mice resembling the phenotype of mucopolysaccharidosis VI. Proc. Natl. Acad. Sci. USA. 93:8214-8219.

7. Hopwood, J.J., A. Vellodi, H.S. Scott, C.P. Morris, T. Litjens, P.R. Clements, D.A. Brooks, A. Cooper, and J.E. Wraith. 1993. Long-term clinical progress in bone marrow transplanted mucopolysaccharidosis type I patients with a defined genotype. J. Inherited Metab. Dis. 16:1024-1033.

8. Hoogerbrugge, P.M., O.F. Brouwer, P. Bordigoni, O. Ringden, P. Kapaun, J.J. Ortega, A. O’Meara, G. Cornu, G. Souillet, D. Frappaz, et al. 1995. Allogeneic bone marrow transplantation for lysosomal storage diseases. Lancet (N. Am. Ed.). 345:1398-1402.

9. Krivit, W., M.E. Pierpont, K. Ayaz, M. Tsai, N.K. Ramsay, J.H. Kersey, S. Weisdorf, R. Sibley, D. Snover, M.M. McGovern, et al. 1984. Bone marrow transplantation in the Maroteaux-Lamy syndrome (mucopolysaccharidosis type VI). Biochemical and clinical status 24 months after transplantation. N. Engl. J. Med. 311:1606-1611.

10. McGovern, M.M., M.D. Ludman, M.P. Short, L. Steinfeld, M. Kattan, E.L. Raab, W. Krivit, and R.J. Desnick. 1986. Bone marrow transplantation in Maroteaux-Lamy syndrome (MPS type 6): status 40 months after BMT. In Bone Marrow Transplantation for Treatment of Lysosomal Storage Diseases. W. Krivit and N. Paul, editors. Birth Defects Orig. Artic. Ser. 22:41-53.

11. Krivit, W. 1992. Maroteaux-Lamy syndrome type VI treatment by allogeneic bone marrow transplantation in six patients and potential for autotransplantation genetic therapy. Int. Pediatr. 7:47.

12. Krivit, W., J.H. Sung, L.A. Lockman, and E.G. Shapiro. 1995. Bone marrow transplantation for treatment of lysosomal and peroxisomal storage diseases: focus on CNS reconstitution. In Principles of Clinical Immunology. Vol. 2. R.R. Rich, T.A. Fleisher, B.O. Schwartz, W.T. Shearer, and W. Strober, editors. Mosby, St. Louis, MO. 1859-1860.

13. Barton, N.W., F.S. Furbish, G.J. Murray, M. Garfield, and R.O. Brady. 1990. Therapeutic response to intravenous infusions of glucocerebrosidase in a patient with Gaucher disease. Proc. Natl. Acad. Sci. USA. 87:1913-1916.

14. Barton, N.W., R.O. Brady, J.M. Dambrosia, A.M. Di Bisceglie, S.H Doppelt, S.C. Hill, H.J. Mankin, G.J. Murray, R.I. Parker, C.E. Argoff, et al. 1991. Replacement therapy for inherited enzyme deficiency-macrophage-targeted glucocerebrosidase for Gaucher's disease. N. Engl. J. Med. 324:14641470 .

15. Hollak, C.E., J.M. Aerts, R. Goudsmit, S.S. Phoa, M. Ek, S. van Weely, A.E. von dem Borne, and M.H. van Oers. 1995. Individualised low-dose aglucerase therapy for type 1 Gaucher's disease. Lancet (N. Am. Ed.). 345:14741478.

16. Vogler, C., M. Sands, A. Higgins, B. Levy, J. Grubb, E.H. Birkenmeier, and W.S. Sly. 1993. Enzyme replacement with recombinant $\beta$-glucuronidase in the newborn mucopolysaccharidosis type VII Mouse. Pediatr. Res. 34:837-840.

17. Sands, M.S., C. Vogler, J.W. Kyle, J.H. Grubb, B. Levy, N. Galvin, W.S. Sly, and E.H. Birkenmeier. 1994. Enzyme replacement therapy for murine mucopolysaccharidosis type VII. J. Clin. Invest. 93:2324-2331.

18. Shull, R.M., E.D. Kakkis, M.F. McEntee, S.A. Kania, A.J. Jonas, and E.F. Neufeld. 1994. Enzyme replacement in a canine model of Hurler syndrome. Proc. Natl. Acad. Sci. USA. 91:12937-12941.

19. Crawley, A.C., D.A. Brooks, V.J. Muller, B.A. Petersen, E.L. Isaac, J. Bielicki, B.M. King, C.D. Boulter, A.J. Moore, N.L. Fazzalari, D.S. Anson, S Byers, and J.J. Hopwood. 1996. Enzyme replacement therapy in a feline model of Maroteaux-Lamy syndrome. J. Clin. Invest. 97:1864-1873.

20. Vogler, C., M.S. Sands, B. Levy, N. Galvin, E.H. Birkenmeier, and W.S Sly. 1996. Enzyme replacement with recombinant $\beta$-glucuronidase in murine mucopolysaccharidosis type VII: impact of therapy during the first six weeks of life on subsequent lysosomal storage, growth, and survival. Pediatr. Res. 39: $1050-1054$. 
21. Haskins, M.E., P.F. Jezyk, and D.F. Patterson. 1979. Mucopolysaccharide storage disease in three families of cats with arylsulfatase B deficiency: leukocyte studies and carrier identification. Pediatr. Res. 13:1203-1210.

22. Gold, E. 1979. A simple spectrophotometric method for estimating glycosaminoglycan concentrations. Anal. Biochem. 99:183-188.

23. Yogalingam, G., T. Litjens, J. Bielicki, A.C. Crawley, V. Muller, D.S. Anson, and J.J. Hopwood. 1996. Feline mucopolysaccharidosis type VI: characterization of recombinant $N$-acetylgalactosamine 4-sulfatase and identification of a mutation causing the disease. J. Biol. Chem. 271:27259-27265.

24. Konde, L.J., M.A. Thrall, P. Gasper, S.M. Dial, K. McBiles, S. Colgan, and M. Haskins. 1987. Radiographically visualized skeletal changes associated with mucopolysaccharidosis VI in cats. Vet. Radiol. 28:223-228.

25. Blumenkrantz, N., and G. Asboe-Hansen. 1973. New method for quantitative determination of uronic acids. Anal. Biochem. 54:484-489.

26. Hopwood, J.J., and J.R. Harrison. 1982. High-resolution electrophoresis of urinary glycosaminoglycans: an improved screening test for the mucopolysaccharidoses. Anal. Biochem. 119:120-127.

27. Berman, E. 1986. Fetal and neonatal growth and development. In Current Therapy in Theriogenology. D.A. Morrow, editor. W.B. Saunders Co., Philadelphia. 801-804.

28. Wenger, D.A., P.W. Gasper, M.A. Thrall, S.M. Dial, R.A. LeCouteur, and E.A. Hoover. 1986. Bone marrow transplantation in the feline model of arylsulfatase B deficiency. In Bone Marrow Transplantation for Treatment of Lysosomal Storage Diseases. W. Krivit and N. Paul, editors. Birth Defects Orig. Artic. Ser. 22:177-186.

29. Haskins, M., H.J. Baker, E. Birkenmeier, P.M. Hoogerbrugge, B.J. Poorthuis, T. Sakiyama, R.M. Shull, R.M. Taylor, M.A. Thrall, and S.U. Walkley. 1991. Transplantation in animal model systems. In Treatment of Genetic Diseases. R.J. Desnick, editor. Churchill Livingstone, New York. 183-201.

30. Norrdin, R.W., K.S. Moffat, M.A. Thrall, and P.W. Gasper. 1993. Characterization of osteopenia in feline mucopolysaccharidosis VI and evaluation of bone marrow transplantation therapy. Bone (NY). 14:361-367.

31. Turner, A.S., R.W. Norrdin, S. Gaarde, H.E. Connally, and M.A. Thrall.
1995. Bone mineral density in feline mucopolysaccharidosis VI measured using dual-energy x-ray absorptiometry. Calcif. Tissue Int. 57:191-195.

32. Aguirre, G., I. Raber, M. Yanoff, and M. Haskins. 1992. Reciprocal corneal transplantation fails to correct mucopolysaccharidosis VI corneal storage. Invest. Ophthalmol. Vis. Sci. 33:2702-2713.

33. Birkenmeier, E.H., J.E. Barker, C.A. Vogler, J.W. Kyle, W.S. Sly, B Gwynn, B. Levy, and C. Pegors. 1991. Increased life span and correction of metabolic defects in murine mucopolysaccharidosis type VII after syngeneic bone marrow transplantation. Blood. 78:3081-3092.

34. Breider, M.A., R.M. Shull, and G. Constantopoulos. 1989. Long-term effects of bone marrow transplantation in dogs with mucopolysaccharidosis I. Am. J. Pathol. 134:677-692.

35. Richards, S.M., T.A. Olson, and J.M. McPherson. 1993. Antibody response in patients with Gaucher disease after repeated infusion with macrophage-targeted glucocerebrosidase. Blood. 82:1402-1409.

36. Menon, K.P., P.T. Tieu, and E.F. Neufeld. 1992. Architecture of the canine IDUA gene and mutation underlying canine mucopolysaccharidosis I. Ge nomics. 14:763-768.

37. Shull, R.M., X. Lu, M.F. McEntee, R.M. Bright, K.A. Pepper, and D.B. Kohn. 1996. Myoblast gene therapy in canine mucopolysaccharidosis I: abrogation by an immune response to $\alpha$-L-iduronidase. Hum. Gene Ther. 7:1595-1603.

38. Di Ferrante, N. 1967. The measurement of urinary mucopolysaccharides. Anal. Biochem. 21:98-106.

39. Varadi, D.P., J.A. Cifonelli, and A. Dorfman. 1967. The acid mucopolysaccharides in normal urine. Biochim. Biophys. Acta. 141:103-117.

40. Alroy, J., G.O. Freden, V. Goyal, S.S. Raghavan, and K.L. Schunk. 1989. Morphology of leukocytes from cats affected with $\alpha$-mannosidosis and mucopolysaccharidosis VI (MPS VI). Vet. Pathol. 26:294-302.

41. Haskins, M.E., S.A. Bingel, J.W. Northington, C.D. Newton, R.D. Sande, P.F. Jezyk, and D.F. Patterson. 1983. Spinal cord compression and hindlimb paresis in cats with mucopolysaccharidosis VI. J. Am. Vet. Med. Assoc. 182:983-985. 